\title{
Laparoendoscopic single-site retroperitoneoscopic adrenalectomy: a matched-pair comparison with the gold standard
}

\author{
Tao-ping Shi $\cdot$ Xu Zhang $\cdot$ Xin Ma $\cdot$ \\ Hong-zhao Li $\cdot$ Jie Zhu $\cdot$ Bao-jun Wang $\cdot$ \\ Jiang-ping Gao $\cdot$ Wei Cai $\cdot$ Juan Dong
}

Received: 10 May 2010/Accepted: 15 November 2010/Published online: 18 December 2010

(C) The Author(s) 2010. This article is published with open access at Springerlink.com

\begin{abstract}
Background Laparoscopic adrenalectomy has become the gold-standard for the surgical treatment of most adrenal lesions. This study evaluated the operative outcome of laparoendoscopic single-site (LESS) retroperitoneoscopic adrenalectomy (LESS-ARA) in comparison with the current standard operation procedure.

Methods Between June and December 2009, 19 patients underwent LESS-ARA, and their outcomes were compared with a contemporary 1:2 matched-pair cohort of 38 patients who underwent standard ARA by the same surgeon. In LESS-ARA, a multichannel port was inserted through a 2.5- to 3.0-cm transverse skin incision below the tip of the 12 th rib. The LESS-ARA procedure was performed using a 5 -mm $30^{\circ}$ laparoscopic camera and two standard laparoscopic instruments. The following parameters were compared between the two groups: demographics, details of the surgery, perioperative complications, postoperative visual analog pain scale score, analgesic requirement, and shortterm measures of convalescence.

Results The finding showed that LESS-ARA and standard ARA were comparable in terms of the estimated blood loss (30 vs $17.5 \mathrm{ml} ; p=0.64$ ), postoperative hospital stay ( 6 vs 6 days; $p=0.67$ ), and postoperative complications ( 2 vs 3 patients; $p=1.00$ ) for patients with similar baseline demographics and median tumor size (2.1 vs 3.0 ; $p=0.18) \mathrm{cm}$. The intraoperative hemodynamic values were similar in the two groups. The LESS-ARA group had
\end{abstract}

T. Shi $\cdot$ X. Zhang $(\bowtie) \cdot$ X. Ma $\cdot$ H. Li $\cdot$ J. Zhu $\cdot$ B. Wang J. Gao $\cdot$ W. Cai - J. Dong

Department of Urology, Chinese People's Liberation Army General Hospital, Military Postgraduate Medical College, 28 Fuxing Road, Haidian District, 100853 Beijing, China e-mail: xzhang@tjh.tjmu.edu.cn a longer median operative time (55 vs $41.5 \mathrm{~min} ; p=$ 0.0004 ), whereas the in-hospital use of analgesics was significantly less (5 vs 12 morphine equivalents; $p=0.03$ ). Conclusions The LESS retroperitoneoscopic adrenalectomy approach is feasible and offers a superior cosmetic outcome and better pain control, with perioperative outcomes and short-term measures of convalescence similar to those of the standard approach, albeit with a longer operative time.

Keywords Adrenalectomy - Case-control study · Convalescence $\cdot$ Laparoscopic surgery $\cdot$ Single incision

Minimal access surgery has inherent appeal for small deeply seated target organs such as the adrenal glands. No other tissue shows a greater distinction between the small size of an organ and the size of the skin incision required for open surgical exposure than that found in adrenal surgery [1]. Laparoscopic adrenalectomy has therefore become the gold standard for adrenal surgery [2]. The anatomic localization of the adrenal glands within the upper retroperitoneum has inspired surgeons to adopt the retroperitoneal approach. Since February 2000, we have been developing an anatomic retroperitoneoscopic adrenalectomy (ARA) technique [3, 4].

Although ARA has a lower morbidity than open surgery, it still requires at least three incisions, each $0.5-2.5 \mathrm{~cm}$ in length. Each of the incisions has the potential to increase the risk of bleeding, pain, hernia, and internal organ damage, compromising the cosmetic outcome [5].

A new alternative to the conventional laparoscopy is laparoendoscopic single-site (LESS) surgery [6]. Early clinical series have demonstrated the feasibility of LESS in urologic procedures, including nephrectomy, pyeloplasty, 
renal cryotherapy, and varicocelectomy [7-9]. We describe a series of patients undergoing LESS anatomic retroperitoneoscopic adrenalectomy (LESS-ARA) and compare the outcomes with those of patients undergoing conventional laparoscopy.

To our best knowledge, our efforts represent the first series of retroperitoneal laparoscopic adrenalectomy via a single multilumen port and the first series of LESS performed in China. Our study also represents the first comparison of the outcomes between LESS and the gold standard laparoscopic adrenalectomy.

\section{Materials and methods}

Participants and study design

A retrospective serial case-control study design was used in this study. Between June and December 2009, LESS-ARA was performed for 19 patients with adrenal tumors after informed consent was obtained. One experienced laparoscopic surgeon (X.Z.) performed all the procedures.

The LESS-ARA procedure was indicated only for unilateral benign adrenal tumors. Patients with tumor diameters greater than $4 \mathrm{~cm}$ were not included in the study because the working space in those patients may represent a challenge [10].

All the cases were evaluated by magnetic resonance imaging preoperatively. The patient characteristics are shown in Table 1. During the same period, 87 standard ARA procedures were performed by the same surgeon. From this cohort, we selected 38 patients to serve as the control group in this study. The 38 patients were matched in a 2:1 ratio to index LESS-ARA cases with respect to patient age, body mass index (BMI), tumor size, laterality, and surgical indication, respectively. No consideration or analysis of surgical parameters and outcomes was made until this control group had been selected based only on preoperative variables. This study was approved by the institutional review board of our hospital.

The data collected from both groups included demographics, details of the surgery, perioperative complications, and short-term measures of convalescence. The operative time was calculated from the start of the skin incision to skin closure. The visual analog pain scale (VAPS) score was recorded from $24 \mathrm{~h}$ after operation to discharge. The pain scale used ranged from 1 (minimal pain) to 10 (worst). The analgesic use from the recovery room to the moment of discharge was converted to morphine equivalents.

\section{Surgical procedures}

The ARA technique is well established. The patient is placed in the full flank position $\left(90^{\circ}\right)$. Pressure points are fully padded. The table is flexed, and the patient is secured with adhesive tape.

For the patients receiving the LESS-ARA procedure, a TriPort (Olympus, Advanced Surgical Concepts, Dublin, Ireland) is used to provide multichannel access through a single incision. A $5-\mathrm{mm} 30^{\circ}$ rigid laparoscope (Olympus Medical, Tokyo, Japan) is used in all cases. Two conventional laparoscopic (straight) instruments (e.g., forceps, harmonic scalpel, and bipolar forceps) are used to perform the procedures.

A 2.5- to 3-cm transverse skin incision is made along the lower margin of the 12th rib in the midaxillary line (Fig. 1). The underlying musculature is spared by blunt splitting of the obliques and transversalis. The thoracolumbar fascia is next exposed and penetrated for entrance

Table 1 Patient demographics

\begin{tabular}{llll}
\hline & LESS-ARA & Standard ARA & $p$ Value \\
\hline No. of patients & 19 & 38 & $57.0(53.0,62.0)$ \\
Median age: years (Q1, Q3) & $57.0(54.0,62.0)$ & $21 / 17$ & 0.96 \\
Male/female & $8 / 11$ & $29.0(25.0,33.4)$ \\
Median BMI (Q1, Q3) & $29.8(26.9,33.1)$ & $2(2,3)$ & 0.35 \\
Median ASA score (Q1, Q3) & $2(2,3)$ & $15 / 23$ & 0.65 \\
Laterality (right/left) & $10 / 9$ & $3.0(2.0,3.5)$ & 0.85 \\
Median tumor size: cm (Q1, Q3) & $2.1(1.9,2.6)$ & 15 & 0.18 \\
No. with adrenal disease & & 11 & 7 \\
Primary aldosteronism & 7 & 5 &
\end{tabular}

LESS-ARA laparoendoscopic single-site retroperitoneoscopic adrenalectomy, BMI body mass index 

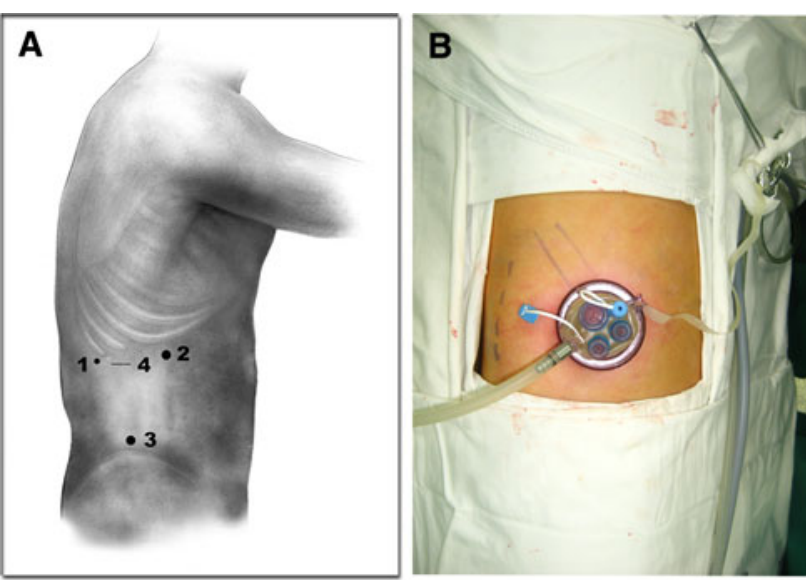

Fig. 1 Incision and port sites for the standard procedure and the laparoendoscopic single-site (LESS) procedure. A Schematic representation of port placement for LESS and standard retroperitoneoscopic adrenalectomies. Ports 1, 2, and 3 were used for standard retroperitoneoscopic adrenalectomy. For the standard procedure, 1 is a $5-\mathrm{mm}$ port below the 12 th rib in the posterior axillary line, 2 is a $12-\mathrm{mm}$ port under the subcostal margin in the anterior axillary line, and 3 is a $10-\mathrm{mm}$ port above the iliac crest in the midaxillary line for the laparoscope. The site indicated by 4 is a $2.5-$ to $3-\mathrm{cm}$ transverse skin incision made below the lower margin of the 12th rib in the midaxillary line for the Triport used in the LESS procedure. B Actual Triport placement for a right LESS retroperitoneoscopic adrenalectomy

to the retroperitoneum. The retroperitoneal space is initially developed using blunt finger dissection to push the peritoneum forward. A balloon dilator (Chenhe Inc., Zhejiang Province, China) then is placed into the retroperitoneal space and inflated with $800 \mathrm{ml}$ of air. The balloon is subsequently deflated, and the introducer of the TriPort aids in the facile introduction of the internal ring into the retroperitoneal space. The TriPort then is fixed as described previously [11]. Carbon dioxide is instilled through the insufflation channel of the TriPort to a maximum pressure of $15 \mathrm{mmHg}$.

Internally, the LESS-ARA surgical technique duplicates the standard ARA [3]. After the Gerota's fascia is incised, the first dissection plane between the perirenal fat and the anterior renal fascia located at the superomedial side of the kidney is explored. The adrenal can be identified at the initial stage of the operation.

Because all the adrenal tumors in this series were smaller than $4 \mathrm{~cm}$, the second dissection plane, between the perirenal fat and the posterior renal fascia located on the lateral side of the upper kidney pole, was omitted in both groups. The dissections proceeded in the avascular plane located on the parenchymal surface of the upper renal pole. The adrenal vein was dealt with at the final stage of the surgery. A detailed photographic representation of the LESS-ARA procedure is shown in Fig. 2.

The isolated adrenal tumor was directly retrieved through the single-port site. Air pressure then was decreased to between 5 and $6 \mathrm{mmHg}$ to identify potential bleeding sites, and complete hemostasis was confirmed. A rubber drainage catheter was left in situ through the incision when necessary. Fascia and skin were carefully sutured to avoid the possible development of a hernia.
Fig. 2 Internal views of the laparoendoscopic single-site retroperitoneoscopic adrenalectomy (LESS-ARA) procedure. A Gerota's fascia is incised longitudinally along the posterior peritoneal reflection (white arrows).B The adrenal tumor (AT) is identified in the first dissection plane between the perirenal fat and the anterior Gerota's fascia (GF) located at the superomedial side of the upper kidney pole (UKP). C By grasping the periadrenal fat cephalad, the bottom of the adrenal gland or tumor is separated from the parenchymal surface of the upper kidney pole, after which the third dissection plane is developed. D The upper adrenal arteries (UAA) are transected
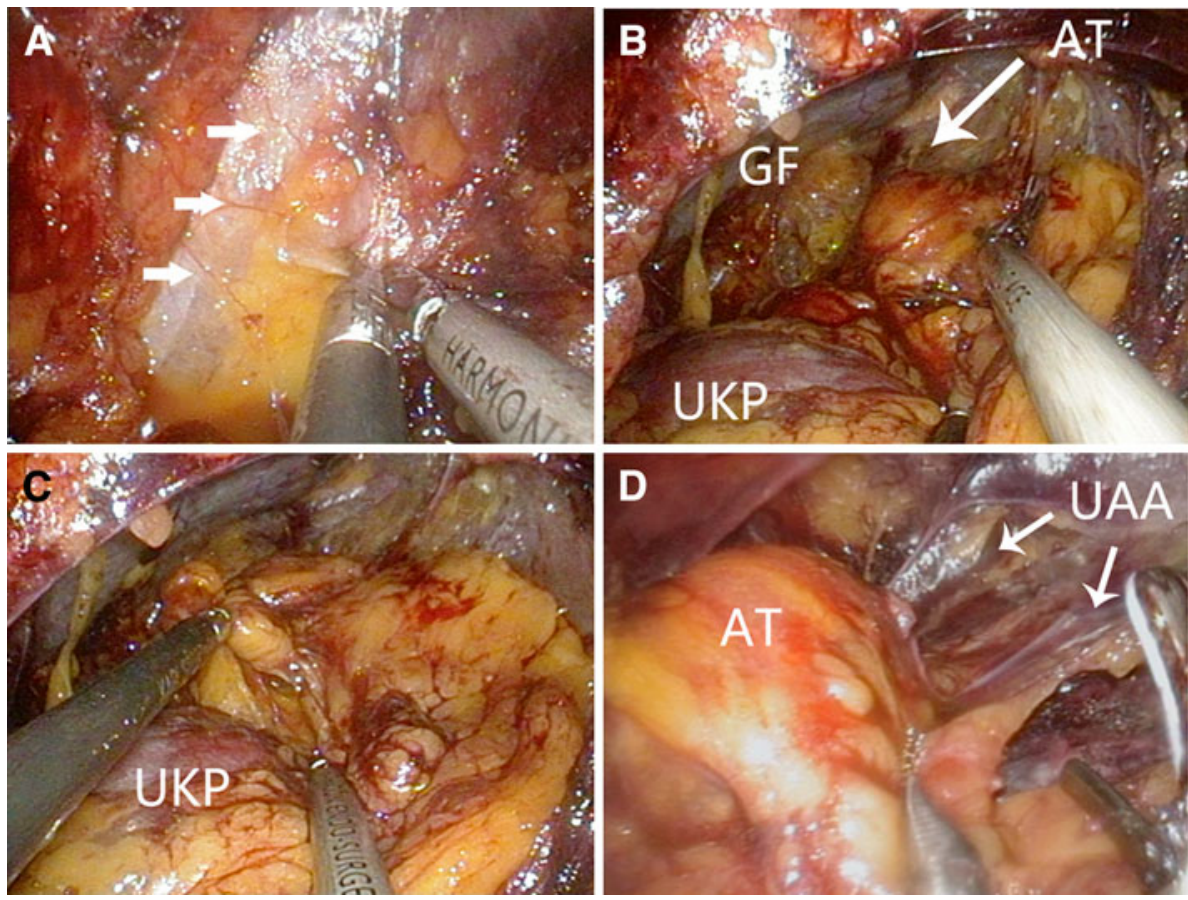
Statistical analysis

Summary statistics are presented as the median and the 25th (Q1) and 75th (Q3) percentiles. Groups were compared using chi-square $\left(\chi^{2}\right)$ analysis, Fisher's exact test, and the Mann-Whitney $U$ test, as appropriate. Statistical significance was set at a $p$ value less than 0.05 , and all reported $p$ values were two-sided. The data analysis was accomplished with SPSS 13.0 (SPSS, Chicago, IL, USA).

\section{Results}

The baseline demographics were comparable between the two groups in terms of patient age, gender, BMI, tumor size, laterality, American Society of Anesthesiology (ASA) class, and surgical indication. The median length of the incision in the LESS-ARA group was $2.8 \mathrm{~cm}$, and the median total length of the three incisions in the standard ARA group was $6.0 \mathrm{~cm}(p<0.0001)$. The LESS-ARA patients had a longer median operative time (55 vs $41.5 \mathrm{~min} ; p=0.0004$ ) but a significantly lower in-hospital analgesic requirement (5 vs 12 morphine equivalents; $p=0.03$ ) than their counterparts in the control group. Four patients in the LESS-ARA group did not require any postoperative analgesia, and only six patients needed pain medication $24 \mathrm{~h}$ after the operation.

No intraoperative complications occurred in either group. The median estimated blood loss (EBL) was $30 \mathrm{ml}$ for the LESS-ARA patients and $17.5 \mathrm{ml}$ for the standard ARA patients $(p=0.64)$. The pheochromocytomas in both groups were excised successfully without any undesirable hemodynamic oscillations. Neither rises in systolic blood pressure to more than $150 \mathrm{mmHg}$ nor decreases to less than $85 \mathrm{mmHg}$ were observed in any of the patients. In addition, neither tachycardic (110 bpm or more) nor bradycardic (50 bpm or less) episodes were observed in either cohort. Table 2 outlines the intraoperative results.

The two procedures were essentially similar in terms of the time to oral intake resumption $(p=0.84)$, time to ambulation $(p=0.14)$, postoperative hospital stay $(p=$ $0.67)$, and convalescence $(p=0.29)$. Postoperative complications occurred for two patients in the LESS-ARA group, including one case each of angina and contralateral atelectasis. In the standard ARA group, two cases of subcutaneous emphysema and one case of radiating shoulder pain occurred. All complications were minor and successfully treated without any surgical intervention (Table 3).

\section{Discussion}

Adrenal surgery represents one of the most successful stories of laparoscopy, particularly in the realm of urology [2]. Rigorous criteria must be fulfilled by any novel treatment before it can become the gold standard. Compared with the established treatment options, the novel alternative must be superior (or at least equivalent) in terms of safety, efficacy, and treatment outcomes [12].

As clinical experience with LESS increases, several crucial points remain, such as the overall intraoperative safety and the postoperative convalescence, which could potentially jeopardize the application of this technique. In

Table 2 Intraoperative results

\begin{tabular}{|c|c|c|c|}
\hline & LESS-ARA & Standard ARA & $p$ Value \\
\hline No. of patients & 19 & 38 & \\
\hline Median incision length: cm (Q1, Q3) & $2.8(2.5,3.0)$ & $6.0(5.5,6.5)$ & $<0.0001$ \\
\hline Median operative time: $\min ^{\mathrm{a}}$ & 55 (47, 63), 38-120 & $41.5(33.75,48.5), 25-110$ & 0.0004 \\
\hline Median EBL: $\mathrm{ml}^{\mathrm{a}}$ & $30(10,100), 5-200$ & $17.5(10,100), 5-150$ & 0.64 \\
\hline \multicolumn{4}{|l|}{ Median intraoperative heart rate (bpm) } \\
\hline Maximum $^{\mathrm{a}}$ & $93(87,98), 82-99$ & $90.5(84.75,95), 80-100$ & 0.27 \\
\hline Mininum $^{\mathrm{a}}$ & $57(52,59), 50-60$ & $56(53,58), 50-59$ & 0.71 \\
\hline \multicolumn{4}{|l|}{ Intraoperative systolic pressure $(\mathrm{mmHg})$} \\
\hline Maximum $^{\mathrm{a}}$ & $136(127,142), 121-145$ & $131.5(125.75,136), 120-144$ & 0.12 \\
\hline Minimum $^{\mathrm{a}}$ & $101(94,104), 87-110$ & 98 (91.25, 104), 86-110 & 0.45 \\
\hline \multicolumn{4}{|l|}{ Median dissection time (min) } \\
\hline First plane $^{\mathrm{a}}$ & $35(23,40), 12-90$ & $23(15,29), 10-90$ & 0.013 \\
\hline Third plane ${ }^{\mathrm{a}}$ & $11(10,16), 4-29$ & $10(8,12), 6-23$ & 0.17 \\
\hline Peritoneum tear $(\%)$ & $4(21.1)$ & $6(15.8)$ & 0.72 \\
\hline
\end{tabular}

LESS-ARA laparoendoscopic single-site retroperitoneoscopic adrenalectomy, $E B L$ estimated blood loss

${ }^{\mathrm{a}}$ Reported as median $(\mathrm{Q} 1, \mathrm{Q} 3)$, range 
Table 3 Postoperative results

\begin{tabular}{llll}
\hline & LESS-ARA & Standard ARA & $p$ Value \\
\hline No. of patients & 19 & 38 & $12(6,20), 1-25$ \\
Median morphine equivalent (mg) & $5(1,13), 0-18$ & $6(5,7)$ & $1(0,2)$ \\
Median VAPS score at 24 h (Q1, Q3) & $5(5,6)$ & $1(1,2)$ & 0.03 \\
Median VAPS score at discharge (Q1, Q3) & $1(1,1)$ & $2(1,2)$ & 0.48 \\
Median days to oral intake (Q1, Q3) & $1(1,2)$ & $6(5,7.25)$ & $3(7.9)$ \\
Median days to ambulation (Q1, Q3) & $2(2,3)$ & $14(10,16.25)$ & 0.14 \\
Median hospital stay: days (Q1, Q3) & $6(5,8)$ & $2(10.5)$ & 14 \\
No. of patients with complications (\%) & $15(12,18)$ & 0.67 \\
Median convalescence days (Q1, Q3) &
\end{tabular}

LESS-ARA laparoendoscopic single-site retroperitoneoscopic adrenalectomy, VAPS visual analog pain scale

${ }^{\mathrm{a}}$ Reported as median $(\mathrm{Q} 1, \mathrm{Q} 3)$, range

this report, we present a 1:2 paired comparison of LESSARA and conventional ARA performed by a single surgeon. Rigorous case-by-case matching was performed to ensure that the control subjects matched the cases as closely as possible with regard to numerous factors other than outcome measures.

No previously published prospective studies have compared LESS with standard laparoscopic surgery. Based on retrospective matched-pair studies, consensus on the advantages of LESS surgery has not been achieved. For example, Raman et al. [13] and White et al. [14] found no difference between nephrectomy and abdominal sacral colpopexy in terms of perioperative outcomes or short-term measures of convalescence. Tracy et al. [15] reported on a cohort of patients undergoing LESS pyeloplasty with more favorable surgical parameters in terms of median operative times (207 vs $237.5 \mathrm{~min} ; p=0.001)$ and median EBL (30 vs $72.5 \mathrm{~mL} ; p=0.002$ ).

Canes et al. [16] compared LESS and standard laparoscopic living donor nephrectomy. The mean warm ischemia time was longer in the LESS group ( 3 vs $6.1 \mathrm{~min}$; $p<0.0001)$. However, allograft function was immediate and comparable between the two groups at 1 and 3 months. Measures of in-hospital morbidity were equivalent. The LESS donor nephrectomy (LESS-DN) approach shortens convalescence, as measured by days that oral pain medication is received after discharge, time off work, and time to resolution of physical symptoms.

Similarly, in our study, in-hospital morphine equivalents were superior in the LESS-ARA group. However, the two groups had a comparable hospital stay (median, 6 vs 6 days), and we did not find any significant difference in the short-term convalescence between the two groups.

Two major reasons for the prolonged hospital stay in both groups might be the governmental health insurance system in China (patients could stay in the hospital longer than needed) and the preference of most patients for staying in the hospital until their silk sutures are removed. However, other postoperative data such as days to oral intake, ambulation, and convalescence are comparable with those of the previous retroperitoneoscopic adrenalectomy study.

To our best knowledge, this study represents the first series of retroperitoneal adrenalectomies using a single multilumen port. Already used in complex procedures, the TriPort allowed us to perform the adrenalectomy through a single small incision. Two case studies have been published previously on the use of lateral transperitoneal LESS for adrenalectomy, with operating times of 120 and $240 \mathrm{~min}$, respectively [17, 18].

Hirano et al. [19] published the first series of patients who received single-port adrenalectomy in 2005. Through a $4.5-\mathrm{cm}$ incision, a $4-\mathrm{cm}$-diameter rectoscope tube was used for direct visualization without insufflation. Although this procedure was not truly laparoscopic, it provided a platform for the evolution of single-port surgery. The average operating time was $203 \mathrm{~min}$. The mean EBL was $252 \mathrm{ml}$, and four patients received blood transfusions.

Walz and Alesina [20] reported five cases of posterior retroperitoneal adrenalectomy using a two-port singleincision technique by a surgeon handling the camera and one instrument simultaneously. The procedure was technically challenging, and such a technique is unlikely to be widely applicable given its difficulty.

Kageyama et al. [21] reported that a gasless and portless endoscopic adrenalectomy could be accomplished via a single minimal incision using a retroperitoneal approach.

The outcomes for all five single-incision laparoscopic adrenalectomy procedures that have been published are listed in Table 4 together with the results of the current study for comparison.

Although umbilical LESS can be used for surgery and leaves virtually no scars, a small LESS-ARA scar on the back generally is acceptable to patients if it results in less 
Table 4 Comparison with previously published experiences with single-minimal-incision adrenalectomy

\begin{tabular}{|c|c|c|c|c|c|c|}
\hline & $\begin{array}{l}\text { Kageyama et al. } \\
{[21]}\end{array}$ & Hirano et al. [19] & $\begin{array}{l}\text { Castellucci et al. } \\
\text { [17] }\end{array}$ & Cindolo et al. [18] & Walz and Alesina [20] & Current study \\
\hline $\begin{array}{l}\text { No. of } \\
\text { patients }\end{array}$ & 30 & 54 & 1 & 1 & 5 & 19 \\
\hline $\begin{array}{l}\text { Tumor } \\
\text { size: cm } \\
\text { (range) }\end{array}$ & $2.7(0.5-6.5)$ & $2.6(0.5-4.5)$ & 4.5 & 4.0 & $2.9(1.0-4.0)$ & $2.4(1.6-4.0)$ \\
\hline BMI & 24.1(17.3-28.8) & $24.5 \pm 3.6$ & - & 29.7 & - & $\begin{array}{l}29.6 \\
\quad(22.8-36.5)\end{array}$ \\
\hline Approach & $\begin{array}{l}\text { Lateral } \\
\text { retroperitoneal }\end{array}$ & $\begin{array}{l}\text { Lateral } \\
\text { retroperitoneal }\end{array}$ & $\begin{array}{l}\text { Lateral } \\
\text { transperitoneal }\end{array}$ & $\begin{array}{l}\text { Lateral } \\
\text { transperitoneal }\end{array}$ & Posterior retroperitoneal & $\begin{array}{l}\text { Lateral } \\
\text { retroperitoneal }\end{array}$ \\
\hline $\begin{array}{l}\text { Length of } \\
\text { incision: } \\
\mathrm{cm} \\
\text { (range) }\end{array}$ & $5.6(3-9)$ & 4.5 & 2.0 & 3.0 & 1.5 & $2.7(2.5-3.0)$ \\
\hline $\begin{array}{l}\text { Operation } \\
\text { time: } \\
\text { min } \\
\text { (range) }\end{array}$ & $147(83-240)$ & $203(92-320)$ & 120 & 240 & $54(35-70)$ & $61.6(38-120)$ \\
\hline $\begin{array}{r}\text { EBL: } \mathrm{ml} \\
\text { (range) }\end{array}$ & $139(5-470)$ & $252(10-1700)$ & 125 & 20 & $<20$ & $53.2(5-200)$ \\
\hline Comments & $\begin{array}{l}\text { Gasless, } \\
\text { portless } \\
\text { endoscopic }\end{array}$ & $\begin{array}{l}\text { Gasless, via a 4-cm- } \\
\text { diameter and 13.7- } \\
\text { cm-length } \\
\text { rectoscope }\end{array}$ & $\begin{array}{l}\text { Three } 5-\mathrm{mm} \text { ports } \\
\text { inserted through } \\
\text { a single incision }\end{array}$ & $\begin{array}{l}\text { First case of an } \\
\text { adrenalectomy with } \\
\text { a single multilumen } \\
\text { port }\end{array}$ & $\begin{array}{l}\text { Two-port single-incision, } \\
\text { with one surgeon handling } \\
\text { the camera and one } \\
\text { instrument }\end{array}$ & \\
\hline
\end{tabular}

Data are given as the means and range

postoperative pain than a standard ARA. Given the anatomic location of the adrenal gland, none of the published transperitoneal LESS adrenalectomies were performed through the umbilicus $[17,18]$.

Lengthening an incision has the potential to diminish the cosmetic appeal of single-port surgery. Therefore, ablative surgery of a small organ, such as an adrenalectomy, may be the most appropriate for LESS. None of the LESS-ARA cases needed extension of the incision for ultimate specimen extraction. However, our exclusion criteria limited tumor size to $4 \mathrm{~cm}$. A similar criterion and accurate imaging will need to be adopted by other surgeons to ensure that enlargement of the incision will not be necessary for removal of the tumor.

Experience with retroperitoneal LESS for urologic diseases is very limited [22, 23]. In urologic laparoscopy, the retroperitoneal approach has some advantages including more direct access to the retroperitoneal organs, less need for visceral retraction, and elimination of the risk for intraperitoneal contamination with tumor cells or infectious organisms [24, 25]. Because the retroperitoneal space is limited, articulable and curved instruments are not as useful as in transperitoneal procedures. The current series of LESS-ARA showed that conventional instrumentation is efficient in minimizing the impact of the reduced triangulation, fog evacuation, and clashing of instruments. However, our extensive experience with standard ARA also is considered to be paramount for the success we had with the LESS-ARA technique.

Overall, our study confirms that the retroperitoneal approach is technically efficient for LESS surgery because it takes advantage of the naturally existing anatomic planes of retroperitoneal organs. Developing an optimal process of dissection and identifying the adrenal gland without destruction of the surrounding anatomical structures were our first impetus to develop ARA [3]. Although the median operative time was significantly longer in the LESS group (by approximately $13.5 \mathrm{~min}$ ), intraoperative issues, such as the adequacy of exposure of the dissection planes around the adrenal gland and manipulation of the adrenal central vein, could be achieved akin to those in the standard ARA approach.

The majority of the extra time required for the surgery comprised dissection of the first plane because of the long distance from the skin incision to this area and the extremely small working space in this phase of the procedure. However, we believe that morbidly obese patients also could benefit from such retroperitoneoscopic access [26, 27]. Although most of the patients in our LESS series were slender, the maximal BMI was $36.5 \mathrm{~kg} / \mathrm{m}^{2}$, and nine 
patients had a BMI greater than $30 \mathrm{~kg} / \mathrm{m}^{2}$. Obesity did not cause any difficulties during port set or dissection in any of these patients.

Nevertheless, a prospective, randomized, controlled trial would be the optimal design for comparing the different surgical approaches. In the absence of such a trial, comparative studies can provide important insights. This study constitutes the first analysis comparing LESS with the gold standard adrenalectomy. Although almost all comparative analyses have been performed without excluding the learning curve effect, our study demonstrates the comparable safety and efficacy of LESS-ARA when the procedures are performed by an experienced surgeon.

The LESS retroperitoneoscopic adrenalectomy is feasible, offering perioperative outcomes and short-term measures of convalescence comparable with those of the standard approach, albeit with a longer operative time. Further large-scale prospective studies of LESS are needed to demonstrate its safety, determine selection criteria, and define its benefits over conventional laparoscopic surgery.

Acknowledgements The National Natural Science Funds for Distinguished Young Scholars, People's Republic of China (no. 30725040), provided the support for this study.

Disclosures Xu Zhang, Xin Ma, Hong-zhao Li, Jie Zhu, Tao-ping Shi, Bao-jun Wang, Jiang-ping Gao, Wei Cai, and Jun Dong have no conflicts of interest or financial ties to disclose.

Open Access This article is distributed under the terms of the Creative Commons Attribution Noncommercial License which permits any noncommercial use, distribution, and reproduction in any medium, provided the original author(s) and source are credited.

\section{References}

1. Guazzoni G, Cestari A, Montorsi F, Lanzi R, Rigatti P, Kaouk JH, Gill IS (2001) Current role of laparoscopic adrenalectomy. Eur Urol 40:8-16

2. Smith CD, Weber CJ, Amerson JR (1999) Laparoscopic adrenalectomy: new gold standard. World J Surg 23:389-396

3. Zhang X, Fu B, Lang B, Zhang J, Xu K, Li HZ, Ma X, Zheng T (2007) Technique of anatomical retroperitoneoscopic adrenalectomy with report of 800 cases. J Urol 177:1254-1257

4. Lang B, Fu B, OuYang JZ, Wang BJ, Zhang GX, Xu K, Zhang J, Wang C, Shi TP, Zhou HX, Ma X, Zhang X (2008) Retrospective comparison of retroperitoneoscopic versus open adrenalectomy for pheochromocytoma. J Urol 179:57-60; discussion 60

5. Suzuki K, Kurumada S, Takeda M, Watanabe R, Go H, Takahashi K (1999) Experience of 100 cases of laparoscopic adrenalectomy in a single urological department. J Urol 161:20

6. Kommu SS, Kaouk JH, Rane A (2009) Laparo-endoscopic singlesite surgery: preliminary advances in renal surgery. BJU Int 103:1034-1037

7. Liatsikos E, Kallidonis P, Kyriazis I, Al-Aown A, Stolzenburg JU (2009) Urologic laparoendoscopic single-site surgery. Nat Rev Urol 6:654-659
8. Canes D, Desai MM, Aron M, Haber GP, Goel RK, Stein RJ, Kaouk JH, Gill IS (2008) Transumbilical single-port surgery: evolution and current status. Eur Urol 54:1020-1029

9. Irwin BH, Rao PP, Stein RJ, Desai MM (2009) Laparoendoscopic single-site surgery in urology. Urol Clin North Am 36:223-235 ix

10. Porpiglia F, Destefanis P, Fiori C, Giraudo G, Garrone C, Scarpa RM, Fontana D, Morino M (2002) Does adrenal mass size really affect safety and effectiveness of laparoscopic adrenalectomy? Urology 60:801-805

11. Rane A, Rao P (2008) Single-port-access nephrectomy and other laparoscopic urologic procedures using a novel laparoscopic port (R-port). Urology 72:260-263; discussion 263-264

12. Liao CH, Lai MK, Li HY, Chen SC, Chueh SC (2008) Laparoscopic adrenalectomy using needlescopic instruments for adrenal tumors less than $5 \mathrm{~cm}$ in 112 cases. Eur Urol 54:640-646

13. Raman JD, Bagrodia A, Cadeddu JA (2009) Single-incision, umbilical laparoscopic versus conventional laparoscopic nephrectomy: a comparison of perioperative outcomes and shortterm measures of convalescence. Eur Urol 55:1198-1204

14. White WM, Goel RK, Swartz MA, Moore C, Rackley RR, Kaouk JH (2009) Single-port laparoscopic abdominal sacral colpopexy: initial experience and comparative outcomes. Urology 74:10081012

15. Tracy CR, Raman JD, Bagrodia A, Cadeddu JA (2009) Perioperative outcomes in patients undergoing conventional laparoscopic versus laparoendoscopic single-site pyeloplasty. Urology 74:1029-1034

16. Canes D, Berger A, Aron M, Brandina R, Goldfarb DA, Shoskes D, Desai MM, Gill IS (2010) Laparo-endoscopic single site (LESS) versus standard laparoscopic left donor nephrectomy: matched-pair comparison. Eur Urol 57:95-101

17. Castellucci SA, Curcillo PG, Ginsberg PC, Saba SC, Jaffe JS, Harmon JD (2008) Single-port-access adrenalectomy. J Endourol 22:1573-1576

18. Cindolo L, Gidaro S, Tamburro FR, Schips L (2010) Laparoendoscopic single-site left transperitoneal adrenalectomy. Eur Urol 57:911-914

19. Hirano D, Minei S, Yamaguchi K, Yoshikawa T, Hachiya T, Yoshida T, Ishida H, Takimoto Y, Saitoh T, Kiyotaki S, Okada K (2005) Retroperitoneoscopic adrenalectomy for adrenal tumors via a single large port. J Endourol 19:788-792

20. Walz MK, Alesina PF (2009) Single-access retroperitoneoscopic adrenalectomy (SARA) — one step beyond in endocrine surgery. Langenbecks Arch Surg 394:447-450

21. Kageyama Y, Kihara K, Kobayashi T, Kawakami S, Fujii Y, Masuda H, Yano M, Hyochi N (2004) Portless endoscopic adrenalectomy via a single minimal incision using a retroperitoneal approach: experience with initial 30 cases. Int J Urol 11:693-699

22. Ryu DS, Park WJ, Oh TH (2009) Retroperitoneal laparoendoscopic single-site surgery in urology: initial experience. J Endourol 23:1857-1862

23. White WM, Goel RK, Kaouk JH (2009) Single-port laparoscopic retroperitoneal surgery: initial operative experience and comparative outcomes. Urology 73:1279-1282

24. Rubinstein M, Gill IS, Aron M, Kilciler M, Meraney AM, Finelli A, Moinzadeh A, Ukimura O, Desai MM, Kaouk J, Bravo E (2005) Prospective, randomized comparison of transperitoneal versus retroperitoneal laparoscopic adrenalectomy. J Urol 174:442-445; discussion 445

25. Sung GT, Gill IS, Hobart M, Soble J, Schweizer D, Bravo EL (1999) Laparoscopic adrenalectomy: prospective, randomized comparison of transperitoneal vs. retroperitoneal approaches. J Urol 161:21 
26. Berglund RK, Gill IS, Babineau D, Desai M, Kaouk JH (2007) A prospective comparison of transperitoneal and retroperitoneal laparoscopic nephrectomy in the extremely obese patient. BJU Int 99:871-874
27. Doublet J, Belair G (2000) Retroperitoneal laparoscopic nephrectomy is safe and effective in obese patients: a comparative study of 55 procedures. Urology 56:63-66 